\title{
Persistence and career choices of female Finnish university physics students
}

\author{
Alexis V. Knaub ${ }^{1}$ and Ramón Barthelemy ${ }^{2}$ \\ ${ }^{1}$ Department of Physics and Astronomy, Michigan State University, East Lansing, MI, USA \\ ${ }^{2}$ Department of Teacher Education, University of Jyväskylä, 40014 Jyväskylä, Finland
}

\begin{abstract}
Finland is often seen and admired as an equity and education-focused country. They have policies that champion gender equity and a world-renowned K-12 education system, with students ranking among the top on international metrics. However, little is known on whether these policies and early education experiences support gender equity in postsecondary education and beyond, particularly in fields that struggle to support women. The few studies that exist indicate that despite having aptitude and national policy that seeks to create gender equity, women may not pursue physics careers. As part of a larger project, we present findings from a study on Finnish physics students enrolled in Finnish universities. Results indicate that students in this study have experiences and attributes that contribute to persisting in physics. When examining these data for gender, we found that women are no more likely to consider leaving physics than men. We also found that female $\mathrm{PhD}$ students tend to be interested in non-academic careers more than men.
\end{abstract}

\section{INTRODUCTION}

Scholars who are interested in improving education and gender equity (e.g., scholars in the US) look to Finland as an exemplar (e.g., [1]). There is evidence that supports these beliefs regarding Finland. One such example is the Program for International Student Assessment (PISA), a test that compares 15-year olds in countries across the world every three years. The PISA regularly indicates that Finnish students are among the top in the world in scientific literacy [2]. In 2015, Finland ranked 5 out of 70 countries on the science literacy portion of PISA and female students had statistically significant $(p<0.05)$ higher scores than male students [3]. In contrast, the US ranked 25 on the same list and male students had statistically significant higher scores on science literacy than female students [3]. Regarding gender equity, Finland as a country has been a leader in this area ranging from being the first country to grant women the right to vote in 1906 to national parental leave for men and women in the 1970s [4]. While Finland's policies that support gender equity are not aimed at scientists, they do address issues that hinder female scientists' success.

Although the secondary school science metrics and national policies suggest a positive environment for girls and women, it is unclear whether girls' high achievement and policies that support women are adequate to encourage women to persist in their pursuit of a science career. In this preliminary study, we analyzed survey results to study Finnish students' persistence in science as well as their interest in pursuing science careers, to determine whether there are any gender differences.

\section{BACKGROUND}

\section{A. The Finland education context}

There is much to be described about the Finnish education context, so for this paper, we focused on aspects relevant to this study rather than a comprehensive description.

During the last two years of high school, students choose different education tracks. One track prepares students for university and the other for vocational institutions. Vocational institutions include more applied fields such as engineering and business, while universities are focused on fields such as physics. Students on the university preparation track are required to take at least one 38-hour course of physics but can take up to six additional 38-hour courses [5]. To ensure that students make the best choices for themselves, Finnish schools provide career guidance for students of all ages [1].

\section{B. Gender and persistance}

In this study, we defined persistence is the decision of students to continue in their field and not consider leaving, their individual anticipation of completing their studies in physics. However, broader systematic issues mean that female students and career scientists may end up leaving their fields despite being talented and interested. In the US, women in graduate programs have reported experiencing different types of sexism ranging from subtle acts known as micro-aggressions to overt sexism [6]. Perceptions of gender bias, regardless of whether discrimination occurs, impacts choice in major [7]. Less obvious issues exist as well. Girls and women may not have strong science identities, which can impact whether they pursue a science career [8].

Much of this work focuses on the US context. Few studies exist on postsecondary education and Finnish students, let alone studies that focus on gender and physics in Finland. There are calls to study the experiences of Finnish female physicists, though some data such as salary, information disaggregated by gender, might be difficult to gather due to legal protections regarding reporting on small sample sizes [9].

The work that does exist suggests that despite the national policies that support gender equity and metrics that suggest female students are just as capable as male students (e.g., [2]), female students may not opt to pursue a science career. One study suggests that girls may not be as interested in pursuing 
science/math compared to boys even when they have comparable grades [10]. Representation of women steadily declines at different career stages $[11,12]$. A little over $10 \%$ of the faculty in Finnish physics departments is female [11, 12]. Female physicists report challenges with balancing work and family life, as well as sexual harassment [13]. In sum, the Finnish context has some key differences but still may have some of the same issues seen elsewhere. Understanding more about this particular context may help deepen the knowledge on gender and physics.

\section{METHODOLOGY}

\section{A. Survey Instrument}

The survey instrument was used as part of a larger study regarding Finnish student persistence in physics. This manuscript presents a few individual items from this survey. These items were from a validated climate survey for LGBT students in higher education [14] and asked respondents to select whether they agreed with a statement. The questions were changed to directly relate to physics education and were written as follows: I have considered leaving my physics major; I feel satisfied with my physics education; If I could go back in time and change my decisions, I would still choose to do my studies in physics. Respondents were asked to select "yes" or "no" for each statement. Items for this study were written in English; from middle school through high school, Finnish students are enrolled in compulsory English classes suggesting they have a good understanding of English.

Respondents were also asked about their career plans. They could select one of the following options: become a teacher, not at a university; continue in academia with the goal of working at a university; find a job in the field of physics but not in academia; find a job outside of physics but not in academia; other (please provide a response).

In addition to the above questions, student demographics were collected across many dimensions, including gender, race, citizenship, degree level, university location and more.

\section{B. Data collection and analysis}

To qualify for participation in this study, students had to be pursuing an undergraduate or graduate degree in physics at a Finnish University. This online survey was sent to Barthelemy's personal contacts across Finland. These individuals were asked to distribute to the survey physics students in their classrooms and department. Because we relied on personal contacts, we do not have a response rate. In all, five out of 9 Finnish institutions offering physics [12] participated in the study.

To ensure that respondents were reading these questions carefully, the survey included a question that asked respondents to select a specific response. If respondents did not select that response, they were removed from the analysis. Furthermore, respondents who did not complete the majority of the survey or who answered questions in a distinguishable pattern (i.e., answering one response for all questions) were also sorted out. Three-hundred twenty-nine usable survey responses were collected.

Data were analyzed using SPSS. We calculated $\chi^{2}$ to determine whether responses were statistically significant and effect size as Cramer's $V$ or $\phi$, for ease of interpretation, to determine how strong relationships between variables were.

\section{Sample description}

The participants in this study were overwhelming Finnish citizens $(N=316,96 \%)$ and ethnically Finnish $(N=305$, $93 \%)$. The majority of participants were male $(N=230,70 \%)$ with less than a third being women $(N=94,29 \%)$ and a few $(N=4,1 \%)$ reporting an "other" gender. One respondent chose not to include their gender. About half the participants were pursuing their bachelor's degree $(N=154,47 \%)$, with the other students pursuing their masters $(N=113,34 \%)$ and PhD. $(N=61,19 \%)$. Their median age was 24.4 years. The respondent representation by university breakdown is as follows:

- University of Jyväskylä (40\%)

- University of Turku (22\%)

- Tampere University of Technology (21\%)

- University of Eastern Finland (12\%)

- University of Oulu (5\%)

\section{Limitations}

This study has two primary limitations. One is we do not know the reasons why respondents responded the way they did. For example, there may be reasons independent of the university and issues within physics that contributed to students contemplating leaving the physics major. We cannot make or suggest causal claims without those data. Our future plans include conducting interviews to learn more about students' experiences.

The other limitation is that the University of Jyväskylä represents almost half of respondents. Perhaps the results would be somewhat different if other institutions were more strongly represented. This is a significant limitation as this particular institution may sway the overall findings. However, this is a first step in exploring university physics education in Finland and offers insight into future work. 
TABLE I. Identity and persistence of students

\begin{tabular}{lcc}
\hline \hline & Yes & No \\
& $N$ (Percentage of respondents) & $N$ (Percentage of respondents) \\
\hline Identified a physicist & $218(66 \%)$ & $110(33 \%)$ \\
Has parent of close relative who was a scientist & $218(66 \%)$ & $110(33 \%)$ \\
Considered leaving major & $124(38 \%)$ & $205(62 \%)$ \\
Satisfied with physics education & $244(74 \%)$ & $85(26 \%)$ \\
Would choose physics again & $276(84 \%)$ & $51(16 \%)$ \\
\hline \hline
\end{tabular}

\section{PRELIMINARY RESULTS}

Aggregate results are in Table I. The majority of students $(66 \%)$ in this study identified as physicists. Those pursuing graduate degree (masters or $\mathrm{PhD}$ ) were more likely to identify as physicists $\left(\chi^{2}(2)=9.008, p=0.011\right)$. There is a small association $(\phi=0.165)$ between identifying as a physicist and pursuing a graduate degree.

The majority of students selected responses that are positive for persisting. Most students were satisfied with their physics education and would choose physics again. However, more than a third of the students $(38 \%)$ considered leaving their major. Even though many students considered leaving the physics major, most students $(84 \%)$ said that they would choose physics again.

$\mathrm{PhD}$ students' career interests are displayed in Table II. We present both broad categories (i.e., Academic career and Nonacademic career) as well as specific careers. Most respondents $(59 \%)$ were interested in pursuing an academic career. Almost all respondents $(N=16$, out of 17) interested in a non-academic career were interested in remaining in physics.

\section{A. Preliminary results, by gender}

We examined the data with respect to gender. Due to few respondents who identified as "other gender", we only present data from respondents who identified as women or men.

One third $(33 \%)$ of the respondents had a parent or close relative who was a scientist. Almost half of the women in this sample ( $N=41,44 \%$ of the total women in this sample) had a scientist in the family whereas a smaller percentage of men $(N=67,29 \%$ of the total men in this sample) had a scientist in their family. The relationship between having a family member who is a scientist and gender is statistically significant, though the relationship between these variables is weak $\left(\chi^{2}(1)=6.435, p=0.040, \phi=0.141\right)$.

We analyzed the following variables by gender: satisfaction with physics education, leaving the physics major, and choosing physics again. The chi-square results for these statements were found statistically insignificant when analyzing for gender. In other words, gender did not have a relationship with these variables.

When examining the career goals into academia and non- academic for $\mathrm{PhD}$ students, a gender difference emerged. Women were significantly more likely to choose a nonacademic route $(N=10$ of 17 female PhD students, $59 \%)$ than men $(N=7$ of 35 male PhD students, $20 \%)\left(\chi^{2}(1)=7.838\right.$, $p=0.005)$. The relationship between gender and academic career is moderately strong $(\phi=0.358)$.

\section{DISCUSSION AND PRELIMINARY CONCLUSIONS}

Our results offer some interesting insights on Finnish students. Most students in this sample identify as a physicists. This result is more pronounced for graduate students, which makes sense given that they chose to continue with their studies. Most students also had a scientist in the family. This may encourage them to pursue science. Interestingly, a higher percentage of women in our sample were related to a scientist than men. Although we do not know whether scientists family members interact with the students in our sample, other research suggests that familial support has a positive impact on physics identity [8]. Recall that physics identity is suggested to contribute to persistence in physics.

It is interesting that many of the students in this study considered leaving the major. That could suggest dissatisfaction, but students also said that they would choose a physics major again and they were satisfied with their physics education. It is unclear why the students in this study selected that response. Further research is needed to understand why they considered leaving physics, as well as why they persisted.

Variables regarding satisfaction and persistence did not have any statistically significant gender differences. That is not to say that the Finnish women and men in this study had the same experiences in physics. We do not have the data to suggest that. However, regardless of what experiences they had, women and men were similar with respect to satisfaction, selecting a physics major, and contemplating leaving physics.

We examined PhD students' interest in careers. Assuming that continuing in academia means continuing in physics in an academic setting, the majority of respondents are interested in remaining in physics. This could suggest a commitment to physics, although we do not know what motivates that commitment (e.g., passion for physics, financial reasons). Further investigation is 
TABLE II. Career choices of PhD students (Total $N=61$ )

\begin{tabular}{l|lll}
\hline \hline & Subcategory & $N$ & Percentage of total respondents \\
\hline $\begin{array}{l}\text { Academic career } \\
(N=36,59 \%)\end{array}$ & Continue in academia, with the goal of working at a university & 36 & $59 \%$ \\
& & & \\
Non-academic career & Become a teacher, not at a university & 0 & $0 \%$ \\
$(N=17,28 \%)$ & Find a job in the field of physics but not in academia & 16 & $26 \%$ \\
& Find a job outside of physics but not in academia & 1 & $2 \%$ \\
Other & & & \\
$(N=8,13 \%)$ & & & $13 \%$ \\
\hline \hline
\end{tabular}

The female doctoral students in this study were more likely to be interested in a non-academic career than men. We are unable to determine why this gender difference occurred, and we cannot determine whether pursing a non-academic career could be considered positive for women. Academic physics positions may be rare in Finland [12], so this result could be interpreted as positive, that women are pursuing viable career options. However, women could also be discouraged from pursuing academic careers either directly (e.g., mentors suggesting non-academic careers) or indirectly (e.g., they may not feel that an academic career is a viable option for women due to few female physicists in Finnish academia).

These preliminary results are seemingly positive with respect to gender and particularly, for women. There are many variables where there is no relationship with respect to gender, suggesting women and men experience no significant differences in physics in Finland. The few variables that suggest a gender difference could be interpreted as positive (i.e., being related to a scientist) or neutral (i.e., interest in nonacademic career). It is possible that the Finnish context, on some level, does not have the same challenges surrounding gender in physics as other countries or even that gender differences in physics, at least between men and women, do not exist.

However, we urge caution before readers make that conclusion. This study contributes to a complex picture of gender in physics in Finland. The data in this study, along with national policies, could be interpreted as women do not experience any gender differences. Yet, other studies suggest that Finnish female physicists do not experience gender equity or even equality [9, 11-13]. More research is needed to truly understand the interplay among policy, this study, and other work before larger conclusions are made.

\section{ACKNOWLEDGEMENTS}

The authors would like acknowledge Fulbright Finland for funding a year long fellowship for Dr. Ramon S. Barthelemy to collect data.
[1] Sahlberg, P. American Educator, 36(1), 20. (2012).

[2] http://gpseducation.oecd.org/CountryProfile?primaryCountry=FIN Retrieved 18 June 2018.

[3] "Science Literacy". National Center for Education Statistics. https://nces.ed.gov/surveys/pisa/pisa2015/ pisa2015highlights_3c.asp. Retrieved 18 June 2018.

[4] Ministry of Social Affairs and Health. "Finland is a gender equality pioneer." https://stm.fi/en/finland-is-a-genderequality-pioneer. Retrieved 18 June 2018.

[5] Finnish National Board of Education. National Core Curriculum for General Upper Secondary Schools. (2015).

[6] Barthelemy, R.S., McCormick, M., \& Henderson, C. Phys. Rev. Phys. Educ. Res, 12, 020119. (2016).

[7] Ganley, C. M., George, C. E., Cimpian, J. R., \& Makowski, M. B. American Educational Research Journal. (2017).
[8] Hazari, Z., Sonnert, G., Sadler, P. M., \& Shanahan, M. C. Journal of Research in Science Teaching, 47(8), 978-1003. (2010).

[9] Miikkulainen, K., \& Vapaavuori, J. Update on women in physics in Finland. AIP Conference Proceedings, 1697(1). (2015).

[10] Chow, A., Eccles, J. S., \& Salmela-Aro, K. Developmental Psychology, 48(6), 1612. (2012).

[11] The Finnish Physical Society and The University of Helsinki, What You Should Know About Women and Physics - Gender Equality at the Physics Department. (2008).

[12] Banzuzi, K., Women in physics in Finland. AIP Conference Proceedings, 102. (2013).

[13] Sannino, A., \& Vainio, J. Gender and Education, 27(5). (2015).

[14] Patridge, E. V., Barthelemy, R. S., \& Rankin, S. R. Journal of Women and Minorities in Science and Engineering, 20(1). (2014). 